Zeszyty Naukowe Szkoły Głównej Gospodarstwa Wiejskiego

Ekonomika i Organizacja Gospodarki Żywnościowej nr 114, 2016: 95-106

Marzena Jeżewska-Zychowicz, Iwona Kowalczuk

Katedra Organizacji i Ekonomiki Konsumpcji

Szkoła Główna Gospodarstwa wiejskiego w Warszawie

\title{
Prozdrowotne i hedonistyczne uwarunkowania decyzji konsumenckich na rynku pieczywa
}

\section{Wstęp}

Tendencje obserwowane na rynku pieczywa wskazują na znaczący spadek jego spożycia. Jedną z przyczyn spadku spożycia chleba w Polsce jest pogorszenie jego jakości, ale również zmiana preferencji konsumentów względem tej grupy produktów [Borowska i Kowrygo 2013]. Zmiany w spożyciu pieczywa skłaniają do podejmowaniu prób wyjaśnienia zjawiska, a także przewidywania przyszłych zachowań konsumentów.

O akceptacji produktu żywnościowego istotnie decydują jego cechy sensoryczne [Arvola i in. 2007; Dean i in. 2007]. $Z$ dotychczasowych badań wynika, że kluczowym czynnikiem wpływającym na pozytywne postrzeganie produktu jest przede wszystkim ocena smaku, co powoduje, że konsumenci poszukują produktów o określonych walorach smakowych [Dean i in. 2007]. Postrzeganie produktów zbożowych, a zwłaszcza pieczywa, jest także w istotnym stopniu warunkowane cechami sensorycznymi, a wśród nich brana jest pod uwagę świeżość, smak, barwa, tekstura [Heenan i in. 2008; Dewettinck i in. 2008].

W trakcie podejmowania decyzji o wyborze żywności ważna dla konsumenta jest jej charakterystyka zdrowotna. Ocenie poddawana jest wartość odżywcza, obecność różnych składników odżywczych oraz składników dodawanych w procesie produkcji [Arvola i in. 2007]. Znaczenie tych cech stwierdzono także w warunkowaniu gotowości spożywania innowacyjnego pieczywa [Baixauli i in. 2008; Ginon i in. 2009].

Zmianom w wielkości i strukturze spożycia żywności towarzyszy poszukiwanie produktów o atrybutach prozdrowotnych, które posiadają pożądane walory sensoryczne [Verbeke 2006; Cox i in. 2004]. 
Celem badania ${ }^{1}$ było określenie znaczenia motywów zdrowotnych oraz hedonistycznych, w tym sensorycznych jako źródła odczuwanej przyjemności, w warunkowaniu chęci spożywania sześciu rodzajów pieczywa poddanych różnym modyfikacjom technologicznym. Przyjęto założenie, że prozdrowotne oraz hedonistyczne motywy wyboru żywności w różny sposób warunkują gotowość do nabywania i spożywania poszczególnych rodzajów pieczywa.

\section{Metody i materiał badawczy}

Badanie zrealizowano we wrześniu 2014 techniką ankieterskich wywiadów osobistych ze wspomaganiem komputerowym w grupie 1014 Polaków w wieku 21 lat i powyżej. Kryteria doboru próby uwzględniały reprezentatywność populacji ze względu na województwo, a następnie dobór miał charakter kwotowy z uwzględnieniem płci, wykształcenia i wielkości miejsca zamieszkania. Do wywiadu kwalifikowano jedynie osoby spełniające kryterium rekrutacyjne, czyli dokonywanie samodzielnych lub we współudziale zakupów żywności. Charakterystyka badanej populacji została przedstawiona w tabeli 1 .

Ocenie poddano deklarowaną chęć do spożywania sześciu rodzajów pieczywa, w tym pieczywa z dodatkiem błonnika, o obniżonej zawartości soli, o obniżonej kaloryczności, z długim terminem przydatności do spożycia, produkowanego bez dodatku substancji konserwujących i spulchniających oraz pieczywa produkowanego na zakwasie, wyrażaną na 5-punktowej skali ocen, gdzie: 1 - nie, 2 - raczej nie, 3 - ani nie, ani tak, 4 -raczej tak, 5 - tak. Częstość spożywania pieczywa jasnego, $\mathrm{z}$ dodatkiem błonnika oraz ciemnego/pełnoziarnistego oceniano na 7-punktowej skali, gdzie: 1 - nie znam, 2 - nigdy, 3-1-3 razy w miesiącu; 4 - raz w tygodniu, 5-2-5 razy w tygodniu, 6 - raz dziennie; 7 - kilka razy w ciagu dnia. W trakcie analizy materiału empirycznego dokonano redukcji liczby kategorii do trzech częstości, a mianowicie: 1 - raz w tygodniu lub rzadziej; 2 - kilka razy w tygodniu; 3 - raz dziennie lub częściej.

W celu wyodrębnienia prozdrowotnych i hedonistycznych motywów warunkujących decyzje konsumentów związane z wyborem żywności wykorzystano wybrane stwierdzenia z Food Choice Questionnaire (Steptoe i in. 1995) dotyczące badanych zagadnień. Wybrano 14 motywów (tabela 1), których znaczenie oceniano na skali 5-punktowej, gdzie: 1 - nieważny, 2 - raczej nieważny, 3 - ani nieważny, ani ważny, 4 - raczej ważny, 5 - bardzo ważny.

\footnotetext{
${ }^{1}$ Praca wykonana w ramach projektu „BIOPRODUKTY, innowacyjne technologie wytwarzania prozdrowotnych produktów piekarskich i makaronu o obniżonej kaloryczności” współfinansowanego z Europejskiego Funduszu Rozwoju Regionalnego w ramach Programu Operacyjnego Innowacyjna Gospodarka 2013-2015.
} 
Tabela 1

Charakterystyka respondentów z uwzględnieniem wybranych cech socjodemograficznych

\begin{tabular}{|c|c|c|}
\hline Grupy respondentów & $\mathrm{N}$ & $(\%)$ \\
\hline \multicolumn{3}{|l|}{ Płeć } \\
\hline Kobieta & 552 & 54,4 \\
\hline Mężczyzna & 462 & 45,6 \\
\hline \multicolumn{3}{|l|}{ Miejsce zamieszkania } \\
\hline Wieś & 373 & 36,8 \\
\hline Miasto od 20 do 99 tys. mieszkańców & 314 & 31,0 \\
\hline Miasto powyżej 100 tys. mieszkańców & 327 & 32,2 \\
\hline \multicolumn{3}{|l|}{ Wykształcenie } \\
\hline Podstawowe & 54 & 5,3 \\
\hline Zasadnicze zawodowe & 240 & 23,7 \\
\hline Średnie & 465 & 45,9 \\
\hline Licencjat i wyższe & 255 & 25,1 \\
\hline \multicolumn{3}{|l|}{ Wiek } \\
\hline 25 lat i mniej & 204 & 20,1 \\
\hline 26-35 lat & 208 & 20,5 \\
\hline $36-45$ lat & 189 & 18,6 \\
\hline $46-55$ lat & 146 & 14,4 \\
\hline Powyżej 55 lat & 267 & 26,3 \\
\hline \multicolumn{3}{|l|}{ Opinia o dochodzie } \\
\hline Jest całkowicie niewystarczający & 42 & 4,1 \\
\hline Pozwala zaspokoić jedynie podstawowe potrzeby & 160 & 15,8 \\
\hline Stać nas na niektóre, ale nie na wszystkie wydatki & 578 & 57,0 \\
\hline Stać nas na wszystko & 176 & 17,4 \\
\hline Stać nas na wszystko i jeszcze możemy zaoszczędzić & 58 & 5,7 \\
\hline
\end{tabular}

Źródło: Badanie własne.

W ramach analizy zebranego materiału empirycznego wykonano analize częstości oraz tabele krzyżowe. Do stwierdzenia różnic istotnych statystycznie między zmiennymi wykorzystano test $\mathrm{Chi}^{2}$ oraz jednoczynnikową analizę wariancji ANOVA przy poziomie istotności $p<0,05$. Do wyboru motywów istotnie różnicujących decyzje konsumentów wykorzystano metodę czynnikową. Obliczono współczynnik adekwatności doboru próby $\mathrm{KMO}(0,913)$ oraz test sferyczności Bartletta $\left(\mathrm{Chi}^{2}-6724,97\right.$; df 91; $<<0,001$. Do wyodrębniania trzech czynników głównych zastosowano metodę rotacji Varimax z normalizacją Kaisera, przy czym zbieżność osiagnięto w 5 iteracji. W dalszych analizach znaczenie 
tych trzech czynników wyrażano jako „nieważny” (wartość średnia - 3 i poniżej) oraz „ważny” (wartość średnia - powyżej 3). W trakcie analiz wykorzystano pakiet statystyczny IBM SPSS Statistics, wersja 21.0

\section{Motywy wyboru żywności}

Wśród 14 motywów warunkujących decyzje i zachowania konsumentów na rynku żywności obejmujących aspekty zdrowotne oraz hedonistyczne jako najważniejszy uznano smak (,,dobrze smakuje”), a następnie zapach (,ładnie pachnie" - tabela 2.

W wyniku redukcji zmiennych wyodrębniono 3 główne motywy różnicujące badaną populację pod względem ich znaczenia w wyborze żywności. Czynnik zdrowotny (I) był reprezentowany przez 5 motywów silnie ze sobą skorelowanych i wyjaśniał 44,9\% wariancji zmiennych. Czynnik sensoryczny (II) obejmował smak, zapach i wygląd żywności wyjaśniał 9,9\% wariancji zmiennych, nato-

Tabela 2

Motywy warunkujące wybór żywności w badanej populacji (Wartości średnie oraz wartości ładunków czynnikowych wyodrębnione na podstawie analizy czynnikowej)

\begin{tabular}{|l|c|c|c|c|}
\hline \multirow{2}{*}{ Opinie na temat motywów } & \multirow{2}{*}{ X; SD* } & \multicolumn{3}{c|}{ Ładunki czynnikowe } \\
\cline { 3 - 5 } & & $\mathrm{I}$ & $\mathrm{II}$ & $\mathrm{III}$ \\
\hline Zawiera dużo witamin i minerałów & 4,$03 ; 0,94$ & $\mathbf{0 , 6 8 6 * *}$ & 0,389 & 0,247 \\
\hline Zawiera naturalne składniki & 4,$07 ; 0,96$ & $\mathbf{0 , 7 3 3}$ & 0,442 & $-0,019$ \\
\hline Niskotłuszczowa & 3,$58 ; 1,10$ & $\mathbf{0 , 6 8 9}$ & 0,009 & 0,220 \\
\hline Bogata w błonnik & 3,$58 ; 1,04$ & $\mathbf{0 , 7 6 8}$ & $-0,025$ & 0,151 \\
\hline Nie zawiera sztucznych składników & 4,$01 ; 0,98$ & $\mathbf{0 , 6 9 5}$ & 0,376 & 0,221 \\
\hline Dobrze smakuje & $\mathbf{4 , 3 2 ; 0 , 8 2}$ & 0,181 & $\mathbf{0 , 8 0 3}$ & 0,003 \\
\hline Ładnie pachnie & $\mathbf{4 , 1 4 ; 0 , 8 7}$ & 0,084 & $\mathbf{0 , 7 1 3}$ & 0,416 \\
\hline Ładnie wygląda & 4,$07 ; 0.89$ & 0,146 & $\mathbf{0 , 7 0 5}$ & 0,324 \\
\hline Pozwala mi się zrelaksować & 3,$56 ; 1,06$ & 0,243 & 0,053 & $\mathbf{0 , 8 1 2}$ \\
\hline Poprawia mi humor & 3,$73 ; 1,06$ & 0,073 & 0,279 & $\mathbf{0 , 7 4 4}$ \\
\hline Posiada przyjemna teksturę & 3,$69 ; 1,05$ & 0,326 & 0,320 & 0,541 \\
\hline Bogata w białko & 3,$78 ; 0,96$ & 0,557 & 0,092 & 0,529 \\
\hline Utrzymuje mnie w zdrowiu & 4,$05 ; 0,98$ & 0,547 & 0,361 & 0,368 \\
\hline Sprawia, że się dobrze czuję & 4,$06 ; 0,92$ & 0,360 & 0,437 & 0,475 \\
\hline
\end{tabular}

*Wartość średnia; odchylenie standardowe, skala 5-punktowa, gdzie 1 - nieważny, 2 - raczej nieważny, 3 - ani nieważny, ani ważny, 4 - raczej ważny, 5 - bardzo ważny.

**Motywy najsilniej skorelowane z czynnikami głównymi (współczynnik korelacji >0,650).

Źródło: Badanie własne. 
miast czynnik hedonistyczny (III), reprezentowany przez dwa motywy, wyjaśniał 7,9\% wariancji zmiennych. Czynnik II i III reprezentował uwarunkowania, które łączą się z postrzeganiem żywności w kategoriach źródła przyjemności. Wyodrębnione czynniki wyjaśniały łącznie $62,8 \%$ wariancji zmiennych (tabela 2 ).

\section{Prozdrowotne i hedonistyczne uwarunkowania częstości spożywania pieczywa}

Najczęściej spożywanym rodzajem pieczywa w badanej populacji było pieczywo jasne. Ponad połowa badanych spożywała ten rodzaj pieczywa przynajmniej 1 raz dziennie, co znajduje potwierdzenie $w$ innych badaniach [Borowska i Kowrygo 2013]. Pieczywo ciemne/pełnoziarniste było spożywane z taką częstością przez nieco ponad $1 / 5$ badanych, a pieczywo $\mathrm{z}$ dodatkiem błonnika tylko przez około $13 \%$ badanych (tabela 3 ).

Tabela 3

Częstość spożywania wybranych rodzajów pieczywa z uwzględnieniem motywów wyboru żywności [\%]

\begin{tabular}{|c|c|c|c|c|}
\hline \multirow[b]{2}{*}{ Motywy } & \multirow{2}{*}{$\begin{array}{c}\text { Znaczenie } \\
\text { motywu }\end{array}$} & \multicolumn{3}{|c|}{ Częstość spożywania } \\
\hline & & $\begin{array}{l}\text { raz w tygodniu } \\
\text { lub rzadziej }\end{array}$ & $\begin{array}{c}\text { kilka razy } \\
\text { w tygodniu }\end{array}$ & $\begin{array}{l}\text { raz dziennie } \\
\text { lub częściej }\end{array}$ \\
\hline \multicolumn{5}{|c|}{ Pieczywo jasne } \\
\hline \multicolumn{2}{|l|}{ Cała populacja } & 30,6 & 15,0 & 54,4 \\
\hline \multirow{2}{*}{ Motywy zdrowotne (IS)* } & nieważny & 26,4 & 17,2 & 56,4 \\
\hline & ważny & 34,4 & 13,0 & 52,6 \\
\hline \multirow{2}{*}{ Motywy sensoryczne (IS) } & nieważny & 38,7 & 17,9 & 43,4 \\
\hline & ważny & 27,6 & 13,9 & 58,5 \\
\hline \multirow{2}{*}{ Motywy hedonistyczne (IS) } & nieważny & 34,1 & 14,7 & 51,1 \\
\hline & ważny & 27,2 & 15,2 & 57,6 \\
\hline \multicolumn{5}{|c|}{ Pieczywo jasne z dodatkiem błonnika } \\
\hline \multicolumn{2}{|l|}{ Cała populacja } & 72,2 & 14,7 & 13,1 \\
\hline \multirow{2}{*}{ Motywy zdrowotne (IS) } & nieważny & 80,4 & 13,2 & 6,4 \\
\hline & ważny & 64,6 & 16,1 & 19,3 \\
\hline \multirow{2}{*}{ Motywy sensoryczne (IS) } & nieważny & 78,8 & 11,3 & 9,9 \\
\hline & ważny & 69,8 & 15,9 & 14,3 \\
\hline \multirow{2}{*}{ Motywy hedonistyczne (IS) } & nieważny & 78,4 & 12,3 & 9,3 \\
\hline & ważny & 66,2 & 17,0 & 16,8 \\
\hline
\end{tabular}


cd. tabeli 3

\begin{tabular}{|c|c|c|c|c|}
\hline \multirow[b]{2}{*}{ Motywy } & \multirow{2}{*}{$\begin{array}{c}\text { Znaczenie } \\
\text { motywu }\end{array}$} & \multicolumn{3}{|c|}{ Częstość spożywania } \\
\hline & & $\begin{array}{l}\text { raz w tygodniu } \\
\text { lub rzadziej }\end{array}$ & $\begin{array}{c}\text { kilka razy } \\
\text { w tygodniu }\end{array}$ & $\begin{array}{l}\text { raz dziennie } \\
\text { lub częściej }\end{array}$ \\
\hline \multicolumn{5}{|c|}{ Pieczywo ciemne/pełnoziarniste } \\
\hline \multicolumn{2}{|l|}{ Cała populacja } & 57,9 & 19,6 & 22,5 \\
\hline \multirow{2}{*}{ Motywy zdrowotne (IS)* } & nieważny & 71,9 & 14,5 & 13,6 \\
\hline & ważny & 45,0 & 24,4 & 30,6 \\
\hline \multirow{2}{*}{ Motywy sensoryczne (IS) } & nieważny & 64,6 & 17,2 & 18,2 \\
\hline & ważny & 55,4 & 20,5 & 24,1 \\
\hline \multirow{2}{*}{ Motywy hedonistyczne (IS) } & nieważny & 63,2 & 17,2 & 19,6 \\
\hline & ważny & 52,8 & 22,0 & 25,2 \\
\hline
\end{tabular}

*Istotne statystycznie różnice między zmiennymi - test Chi ${ }^{2}$ przy $\mathrm{p}<0,05$.

Źródło: Badanie własne.

W przypadku wszystkich rodzajów pieczywa opinia o znaczeniu poszczególnych motywów w wyborze żywności istotnie różnicowała deklarowaną częstość spożywania. Istotnie więcej osób spożywało przynajmniej 1 raz dziennie pieczywo jasne, gdy motywy zdrowotne uznane zostały za nieważne, a motywy sensoryczne i hedonistyczne za ważne. Z kolei więcej osób spożywało ten rodzaj pieczywa 1 raz w tygodniu lub rzadziej, gdy motywy zdrowotne były ważne, a pozostałe - nieważne. Zatem wybór tego pieczywa był w większym stopniu warunkowany względami hedonistycznymi niż zdrowotnymi. W przypadku pieczywa z dodatkiem błonnika oraz pieczywa ciemnego/pełnoziarnistego częstsza konsumpcja łączyła się z traktowaniem wszystkich motywów jako ważnych, a rzadkie spożywanie (1 raz w tygodniu lub rzadziej) - $\mathrm{z}$ ich oceną jako nieważnych (tabela 3). Oznacza to, ze w trakcie wyboru tych rodzajów pieczywa motywy hedonistyczne i zdrowotne warunkują podobnie postępowanie konsumenta.

\section{Prozdrowotne i hedonistyczne uwarunkowania zamiarów nabywania innowacyjnego pieczywa}

Ponad 1/3 badanych osób zadeklarowała gotowość do nabywania pieczywa bez dodatku substancji konserwujących i spulchniających oraz tyle samo osób wskazało pieczywo na zakwasie, co wskazuje na zainteresowanie badanych naturalnością produktu. Relatywnie najmniej osób chciało kupować pieczywo o wydłużonym terminie przydatności do spożycia $(15,5 \%)$ i jednocześnie najwięcej osób $(14,8 \%)$ nie deklarowało zamiaru kupowania tego pieczywa (tabela 4). 
Tabela 4

Zamiar nabywania wybranych rodzajów pieczywa z uwzględnieniem motywów wyboru żywności [\%]

\begin{tabular}{|l|c|c|c|c|c|}
\hline \multirow{2}{*}{\multicolumn{1}{|c|}{ Rodzaje pieczywa }} & \multicolumn{5}{|c|}{ Zamiar kupowania } \\
\cline { 2 - 6 } & nie & $\begin{array}{c}\text { raczej } \\
\text { nie }\end{array}$ & $\begin{array}{c}\text { ani tak, } \\
\text { ani nie }\end{array}$ & $\begin{array}{c}\text { raczej } \\
\text { tak }\end{array}$ & tak \\
\hline Pieczywo z dodatkiem błonnika & 5,6 & 9,8 & 25,1 & 41,8 & 17,7 \\
\hline Pieczywo z obniżoną zawartością soli & 6,5 & 14,9 & 24,8 & 35,3 & 18,5 \\
\hline Pieczywo o obniżonej kaloryczności & 7,0 & 13,5 & 25,4 & 34,0 & 20,1 \\
\hline $\begin{array}{l}\text { Pieczywo o długim terminie przydatności } \\
\text { do spożycia }\end{array}$ & 14,8 & 17,6 & 21,1 & 31,0 & 15,5 \\
\hline $\begin{array}{l}\text { Pieczywo bez dodatku substancji } \\
\text { konserwujących, spulchniających }\end{array}$ & 4,5 & 6,0 & 18,5 & 36,4 & 34,6 \\
\hline Pieczywo na zakwasie & 3,6 & 5,1 & 21,3 & 35,1 & 34,9 \\
\hline
\end{tabular}

Źródło: Badanie własne.

W przypadku pieczywa z dodatkiem błonnika, z obniżoną zawartością soli oraz o obniżonej kaloryczności około $25 \%$ badanych wskazało odpowiedź neutralną ,,ani tak, ani nie", co wskazuje na brak zdecydowania w stosunku do tych produktów.

W przypadku pieczywa z dodatkiem błonnika, z obniżoną zawartością soli oraz o obniżonej kaloryczności opiniom o ważnym znaczeniu motywów zdrowotnych, sensorycznych i hedonistycznych towarzyszyła większa chęć nabywania produktów wyrażana większą wartością średnią (tabela 5).

Większa chęć nabywania produktów znalazła to także potwierdzenie w odsetkach osób deklarujących zamiar nabywania poszczególnych produktów (tabela 5).

Podobne rezultaty otrzymano w przypadku pieczywa bez dodatku substancji konserwujących i spulchniających oraz pieczywa na zakwasie, tj. opiniom o ważnym znaczeniu motywów zdrowotnych, sensorycznych i hedonistycznych towarzyszyła większa chęć nabywania produktów (tabela 6).

Po uwzględnieniu poszczególnych motywów nie wykazano natomiast różnic $\mathrm{w}$ wartościach średnich ocen w odniesieniu do pieczywa o długim terminie przydatności do spożycia. Niemniej jednak istotnie więcej osób wskazywało odpowiedź „tak” wtedy, gdy motywy zdrowotne, sensoryczne i hedonistyczne były ważne w trakcie wyboru żywności (tabela 6).

Uzyskane wyniki badania własnego potwierdzają istotne znaczenie zarówno motywów hedonistycznych, jak i zdrowotnych w warunkowaniu wyboru pieczywa aktualnie spożywanego oraz zamiaru nabywania pieczywa o potencjalnie korzystnych cechach, co znajduje potwierdzenie także w innych badaniach [Hellyer $i$ in. 2012; Vassallo i in. 2009]. 
102

Tabela 5

Zamiar nabywania wybranych rodzajów innowacyjnego pieczywa z uwzględnieniem motywów wyboru żywności [\%]

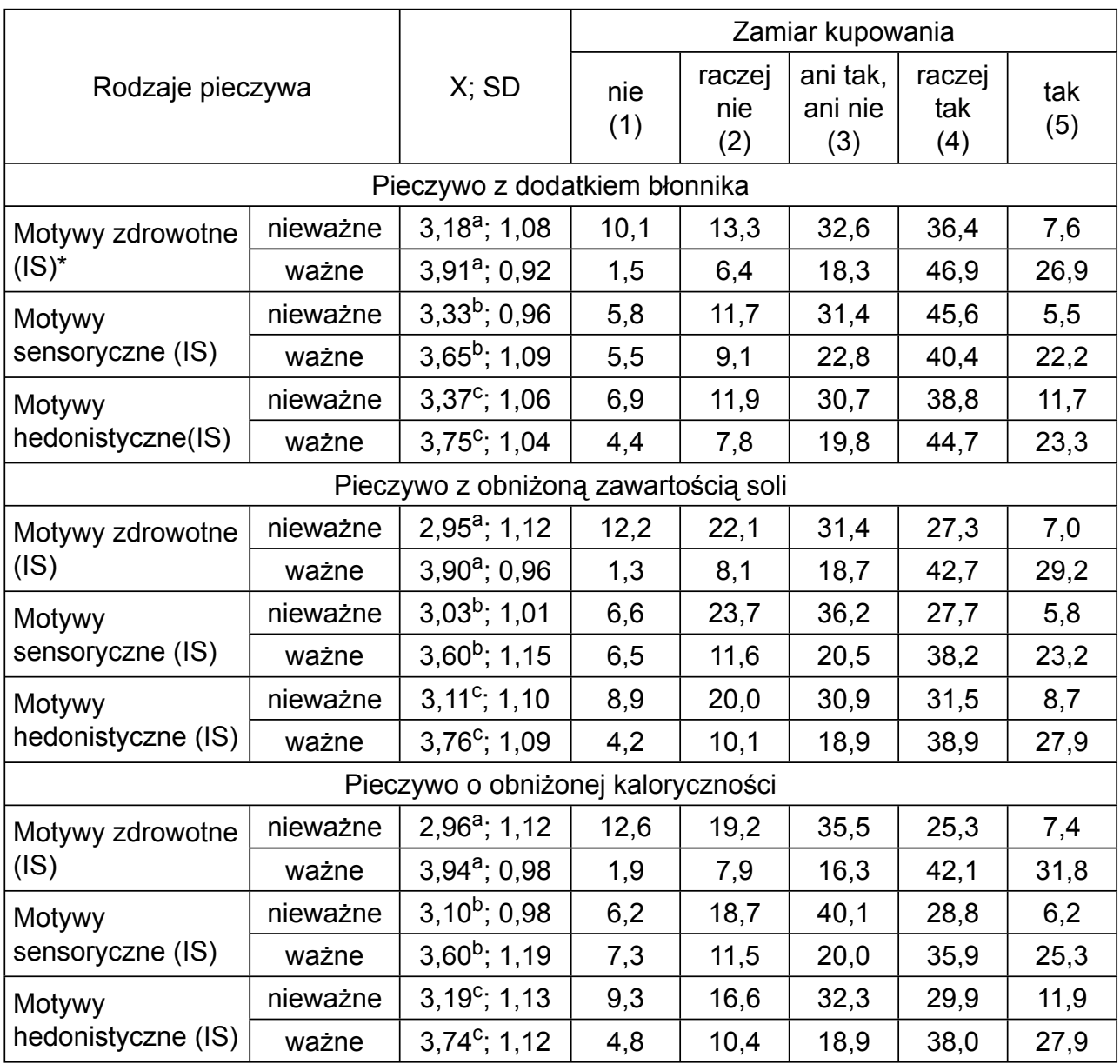

*Istotne statystycznie różnice między zmiennymi - test $\mathrm{Chi}^{2}$ przy $p<0,05$.

$a, b, c$ Wartości średnie oznaczone tymi samymi literami różnią się istotnie statystycznie (ANO$\mathrm{VA}, \mathrm{p}<0,05)$.

Źródło: Badanie własne.

Dla współczesnego konsumenta żywność i jej spożywanie stanowi istotne źródło przyjemności. Może to być wynik akceptacji cech produktu, ale również konsekwencja procesu wychowania czy dobrego samopoczucia. Pozytywne emocje ujawniają się w deklarowanej gotowości do określonych zachowań oraz w obserwowanych zachowaniach [Cox i in. 2004; Ares i in. 2010]. W świetle uzyskanych wyników pieczywo stanowi, podobnie jak wiele innych rodzajów żywności, źródło przyjemności, co wykazano zwłaszcza w przypadku częstości 
Tabela 6

Zamiar nabywania wybranych rodzajów innowacyjnego pieczywa z uwzględnieniem motywów wyboru żywności [\%]

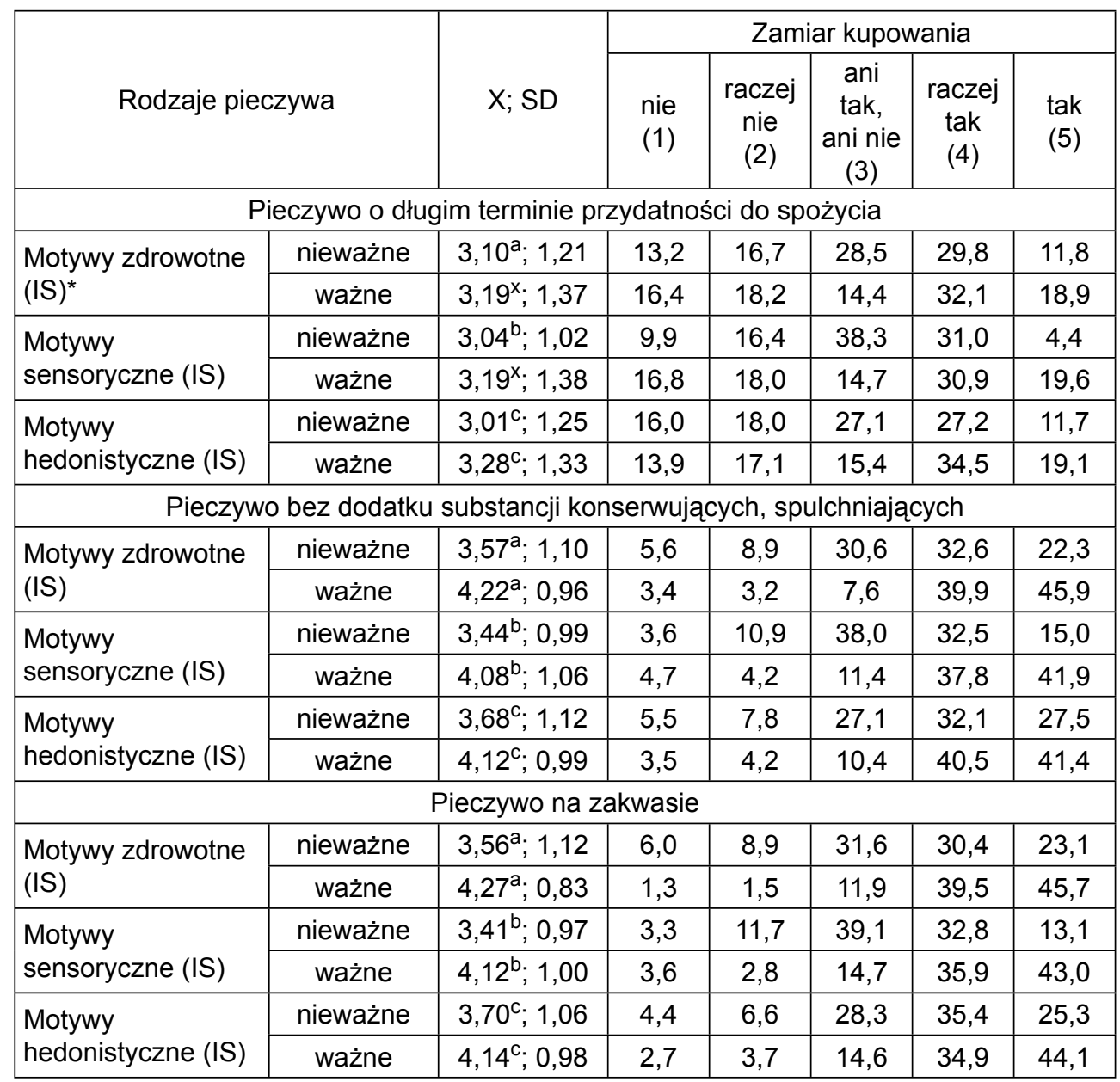

*Istotne statystycznie różnice między zmiennymi - test $\mathrm{Chi}^{2}$ przy $\mathrm{p}<0,05$.

$a, b, c, x$ Wartości średnie oznaczone tymi samymi literami różnią się istotnie statystycznie (ANOVA, $p<0,05)$.

Źródło: Badanie własne.

spożywania pieczywa jasnego. Znaczenie motywów zdrowotnych w podejmowaniu decyzji związanych $\mathrm{z}$ konsumpcją pieczywa zaznacza się w odniesieniu do pieczywa o prozdrowotnej charakterystyce, tj. $z$ dodatkiem błonnika, o obniżonej zawartości soli, o obniżonej kaloryczności, bez dodatków spulchniających i konserwujących oraz produkowanego na zakwasie. 


\section{Podsumowanie}

Z przeprowadzonej analizy wynika, że:

1. Motywy zdrowotne i hedonistyczne w różnym stopniu warunkowały decyzje konsumentów związane $\mathrm{z}$ nabywaniem pieczywa tylko w przypadku pieczywa jasnego. Motywy hedonistyczne sprzyjały częstszej konsumpcji tego pieczywa, podczas gdy większe znaczenie przypisywane motywom zdrowotnym było czynnikiem ograniczającym spożywanie pieczywa z mąki jasnej.

2. Znaczenie przypisywane motywom zdrowotnym i hedonistycznym w wyborze żywności nie różnicowało istotnie deklarowanej chęci nabywania pieczywa o długim terminie przydatności do spożycia.

3. W stosunku do pieczywa o cechach prozdrowotnych, tj. pieczywa ciemnego/pełnoziarnistego, z dodatkiem błonnika, o obniżonej zawartości soli, o obniżonej kaloryczności, bez dodatku substancji spulchniających i konserwujących oraz pieczywa na zakwasie wykazano istotne zróżnicowanie deklaracji badanych osób. Zarówno osoby deklarujące duże znaczenie motywów zdrowotnych, jaki hedonistycznych w warunkowaniu wyboru żywności wykazywały większą skłonność do spożywania tych rodzajów pieczywa w porównaniu z osobami, które określiły znaczenie tych motywów jako nieważne.

Wyniki badania wskazują zatem, że wybór nowych rodzajów pieczywa o zmodyfikowanych cechach w kierunku zwiększenia ich walorów zdrowotnych był warunkowany zarówno czynnikami zdrowotnymi, jak i hedonistycznymi. Oznacza to, że konsumenci doceniając walory zdrowotne takiej żywności, oczekiwali, że jej spożywanie będzie źródłem pozytywnych emocji i doświadczeń w trakcie i po spożyciu.

\section{Literatura}

ARES G., BESIO M., GIMÉNEZ A., DELIZA R., 2010: Relationship between involvement and functional milk deserts intention to purchase. Influence of attitude towards packaging characteristics. Appetite, vol. 55, s. 298-304.

ARVOLA A., LÄHTEENMÄKI L., DEAN M., VASSALLO M., WINKELMANN M., CLAUPEIN E., SABA A., SHEPHERD R., 2007: Consumers' beliefs about whole and refined grain products in the UK, Italy and Finland. Journal of Cereal Sciences, vol. 46, s. $197-206$.

BAIXAULI R., SALVADOR A., HOUGH G., FISZMAN S.M., 2008: How information about fibre (traditional and resistant starch) influences consumer acceptance of muffins. Food Quality and Preference, vol. 19, s. 628-635 
BOROWSKA A., KOWRYGO B., 2013: Innowacyjność produktowa na przyktadzie sektora piekarskiego. Wyd. SGGW, Warszawa.

COX D.N., KOSTER A., RUSSELL C.G., 2004: Predicting intentions to consume functional foods and supplements to offset memory loss using an adaptation of protection motivation theory. Appetite, 2004, vol. 33, s. 55-64.

DEAN M., RAATS M.M., SHEPHERD R., ARVOLA A., LÄHTEENMÄKI L., SABA A., 2007: Consumer perceptions and expectations for healthy cereal products. Journal of Cereal Science, vol. 46, s. 188-196.

DEWETTINCK K., VAN BOCKSTAELE F., KÜHNE B., VAN DE WALLE D., COURTENS T.M., GELLYNCK X., 2008: Nutritional value of bread: Influence of processing, food interaction and consumer perception. Journal of Cereal Science, vol. 48, 243-257.

GINON E., LOHEAC Y., MARTIN C., COMBRIS P., ISSANCHOU S., 2009: Effect of fibre information on consumer willingness to pay for French baguettes. Food Quality and Preference, vol. 20, s. 343-352.

HEENAN S., DUFOUR J.P., HARVEY W., DELAHUNTY C., 2008: The Sensory Quality of Fresh Bread: Consumers' Perceptions, Descriptive Attributes, and Volatile Composition. Food Research International, vol. 41, s. 989-997.

HELLYER N.E., FRASER I., HADDOCK-FRASER J., 2012: Food choice, health information and functional ingredients: An experimental auction employing bread. Food Policy, vol. 37, s. 232-245.

STEPTOE A., POLLARD T.M., WARDLE J., 1995: Development of a measure of the motives underlying the selection of food: the Food Choice Questionnaire. Appetite, vol. 25, s. $267-284$.

VERBEKE W., 2006: Functional foods: Consumer willingness to compromise on taste for health? Food Quality and Preference, vol. 17, s. 126-131.

VASSALLO M., SABA A., ARVOLA A., DEAN M., MESSINA F., WINKELMANN M., CLAUPEIN E., LÄHTEENMÄKI L., SHEPHERD R., 2009: Willingness to use functional breads. Applying the Health Belief Model across four countries. Appetite, vol. 52, s. $452-460$.

\section{Abstrakt}

Celem badania było określenie znaczenia motywów zdrowotnych oraz hedonistycznych, w tym sensorycznych, w warunkowaniu chęci spożywania sześciu rodzajów pieczywa poddanych różnym modyfikacjom technologicznym. Badanie zrealizowano we wrześniu 2014 roku w grupie 1014 Polaków w wieku 21 lat i powyżej.

Większe znaczenie przypisywane motywom hedonistycznym sprzyjało częstszej konsumpcji pieczywa jasnego, podczas gdy motywy zdrowotne były czynnikiem ograniczającym spożywanie tego pieczywa. Znaczenie obydwu motywów nie różnicowało istotnie deklarowanej chęci nabywania pieczywa o długim terminie przydatności do spożycia. W stosunku do pieczywa o cechach prozdrowotnych zarówno osoby deklarujące duże znaczenie motywów zdrowot- 
nych, jak i hedonistycznych w warunkowaniu wyboru żywności wykazywały większą skłonność do jego spożywania w porównaniu z osobami, które określiły znaczenie tych motywów jako nieważne.

Wybór nowych rodzajów pieczywa o zmodyfikowanych cechach w kierunku zwiększenia ich walorów zdrowotnych był warunkowany zarówno motywami zdrowotnymi, jak i hedonistycznymi. Oznacza to, że konsumenci doceniając walory zdrowotne takiej żywności, oczekiwali, że jej spożywanie będzie także źródłem pozytywnych emocji i doświadczeń w trakcie spożywania i po spożyciu.

Słowa kluczowe: konsument, rynek pieczywa, konsumpcja, uwarunkowania spożycia

\section{Pro-health and hedonistic determinants of consumers' decisions on the bread market}

\section{Abstract}

The aim of the study was to determine the importance of healthy and hedonistic motives, including sensory aspects, in conditioning the willingness to consume six sorts of bread with various technological modifications. The research was conducted in September 2014 in a group of 1014 Poles aged 21 and above.

A greater importance attributed to hedonistic motives favoured more frequent consumption of white bread, while the health motives were a factor limiting the consumption of this kind of bread. The importance of both motives did not diversify significantly declared willingness to eat bread with a long shelf life. Participants who declared greater importance of health and hedonistic motives demonstrated greater willingness to eat bread with healthy modifications compared with those who claimed that these motives were not important to them.

The choice of bread with modifications aiming at increasing its health value was determined both by health and hedonistic motives. This means that consumers appreciated the health benefits of such food, but simultaneously expected positive emotions and experiences during and after its consumption.

Key words: consumer, bread market, consumption, factors determining consumption 